\title{
NORMAL/TRISOMY 13-15 MOSAICISM IN TWO INFANTS
}

\author{
BY
}

\author{
A. D. BAIN, J. INSLEY, D. M. DOUGLAS, I. K. GAULD, and H. A. SCOTT \\ From the Department of Pathology, Royal Hospital for Sick Children, Edinburgh, and the \\ Departments of Pathology and Child Life and Health, The University, Edinburgh
}

(RECEIVED FOR PUBLICATION OCTOBER 21, 1964)

It is generally accepted that there is a recognizable clinical syndrome associated with trisomy for one of the 13-15 group of chromosomes. The clinical features of this trisomic syndrome were first described by Patau, Smith, Therman, Inhorn, and Wagner (1960). In a recent paper Smith, Patau, Therman, Inhorn, and DeMars (1963) described a series of 7 cases and reviewed 7 others. The majority of the infants were either stillborn or died in early infancy with cardiac or cerebral malformations.

It is perhaps surprising that only three instances of mosaicism for trisomy 13-15 have been reported (Warkany, Rubinstein, Soukup, and Curless, 1962; Beçak, Beçak, and Schmidt, 1963). The two infants described in this paper show some of the features associated with trisomy 13-15 and have a proportion of their cells trisomic for a 13-15 chromosome.

\section{Case Reports}

Case 1. A female infant, birth weight $8 \mathrm{lb} .1 \frac{1}{2} \mathrm{oz}$. $(3,670 \mathrm{~g}$.), was born at 41 weeks' gestation after a normal pregnancy. The father and mother, both aged 22, were well and unrelated.

At birth the infant was limp, breathed poorly, but responded to simple resuscitation. The following abnormal features were noted: small receding chin (Fig. 1), central cleft of soft palate extending to junction with hard palate, and port wine stain over occiput extending down over the upper part of the neck. Right hand: flexion of middle and ring fingers; the forefinger was flexed over the middle finger; the little finger was long and curved inwards at the junction of the proximal and middle phalanx. Left hand: the little finger was long and flexed inwards at the terminal phalangeal joint. The feet were large and flat but not rocker-bottomed. The eyes, lips, and skull were normal.

The infant was lethargic, did not suck, and during the first 24 hours frequently regurgitated. Twelve hours after birth she had frequent apnoeic cyanotic attacks, followed later by generalized convulsions. She died 44 hours after birth.

Necropsy revealed further abnormalities. The heart was slightly enlarged; there was a large abnormally patent foramen ovale; a small high interventricular septal defect; a large ductus arteriosus; there was no coarctation of the aorta. There was a defect in the anterior part of the falx. The brain showed poorly developed olfactory nerves but no other macroscopical abnormality. The uterus was large and septate. There was no renal or urinary tract abnormality. Buccal and bladder smears showed normal sex chromatin.

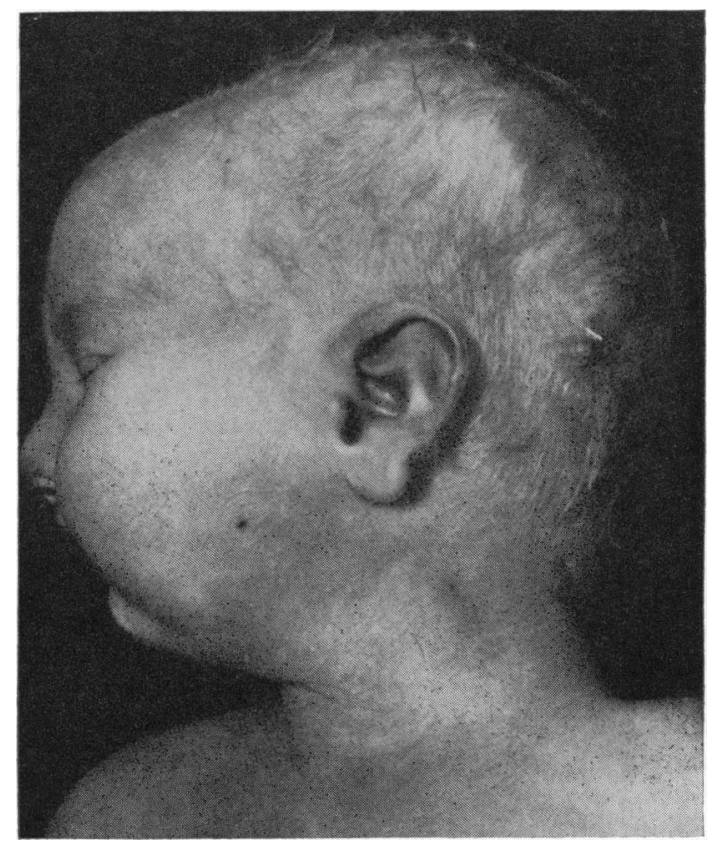

Fig. 1.-Appearance of Case 1.

Case 2. A male infant, birthweight $8 \mathrm{lb} .14 \mathrm{oz}$. $(4,024 \mathrm{~g}$.), was born at 42 weeks' gestation following surgical induction of labour. Moderate hypertension was noted in the fifth month of pregnancy, but this did not progress. The mother, aged 29 years, the father, aged 33 years, and two brothers, aged $5 \frac{1}{2}$ and $3 \frac{1}{2}$ years, were well. The parents were not related.

The infant was slow to breathe at birth. Subsequently he fed poorly with increasing breathlessness. The features were those seen in Fig. 2. The head was big in 


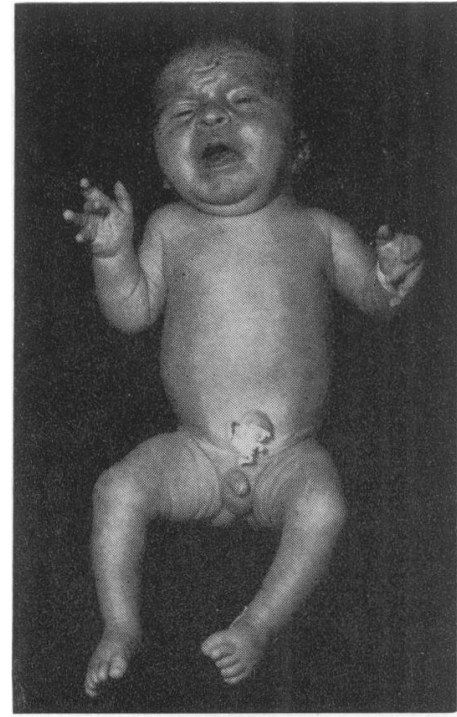

Fig. 2.-Appearance of Case 2.

comparison with the trunk, occipito-frontal circumference was 14.25 in. $(36 \mathrm{~cm}$.); the features were coarse; the forehead sloped backwards and the skin was grossly wrinkled; the ears were low-set. The hands showed flexion deformities of the right middle fingers and to a lesser extent of the other fingers; there was ulnar deviation of both hands, the left more than the right. The nipples were set widely apart. The heart was enlarged with a short grade II systolic murmur audible in the pulmonary area and just audible at the back of the neck. A chest radiograph confirmed cardiac enlargement. The eyes, lips, palate, and feet were normal.

Cardiac failure was diagnosed and the infant was digitalized. He died after a series of cyanotic attacks at the age of 6 weeks.

Necropsy revealed considerable cardiac enlargement particularly involving the left ventricle which showed pronounced hypertrophy of its walls. There was a subaortic stenosis; the aortic valve and the aorta were normal. The anterior part of the falx cerebri was fenestrated. The brain showed no macroscopical abnormality. There was no abnormality of the kidneys and urinary tract. Bladder and buccal smears were negative for sex chromatin.

\section{Chromosome Analysis}

Satisfactory chromosome preparations were obtained from peripheral blood in Case 2, using a modification of the technique of Moorhead, Nowell, Mellman, Battips, and Hungerford (1960). In Case 1, the infant died shortly after admission to hospital and only post-mortem studies could be carried out. For this purpose lymphocyte cultures were prepared from thymus and spleen using the technique of Bain and Gauld (1964).
In both cases a proportion of cells showed 47 chromosomes, the extra one being in the 13-15 group (Fig. 3). The results are summarized in the Table.

Chromosomes were examined from the peripheral blood of each of the parents of both infants and were found to be normal.

TABLE

\begin{tabular}{|c|c|c|c|c|c|c|}
\hline & \multicolumn{6}{|c|}{ No. of Chromosomes } \\
\hline & $<45$ & 45 & 46 & 47 & 48 & $>48$ \\
\hline $\begin{array}{ll}\text { Case } 1 & \left\{\begin{array}{l}\text { Thymus } \\
\text { Spleen }\end{array}\right. \\
\text { Case } 2 & \ldots\end{array}$ & E & $\frac{-}{1}$ & $\begin{array}{l}23 \\
12 \\
36\end{array}$ & $\begin{array}{r}8 \\
21 \\
14\end{array}$ & E & 二 \\
\hline
\end{tabular}

\section{Discussion}

These infants presented clinical features which bore some resemblance to those described for the fully developed trisomy 13-15 syndrome. They were unlike the three previously recorded cases of mosaicism involving an extra 13-15 chromosome.

The clinical features usually associated with trisomy 13-15 are as follows: anomalies of the eyeball; polydactyly and/or fixed finger flexion; deformed or low-set ears; cleft palate; deformities of the external genitalia and/or undescended testes in the male and septate uterus in the female; various heart defects; gross deformity of the brain; hare-lip; haemangiomata, and simian palm creases. Most survivors were judged to be mentally retarded and deaf. Many suffered recurrent apnoeic or convulsive episodes.

One infant, however (Marshall, Newnham, Rawstron, Ellis, and Stevens, 1964), who presented most of these features, was found to have a normal karyotype.

The two mosaics described here did not fully conform to the pattern of a 13-15 trisomy. The disproportionately large head, the coarse facies, and deep wrinkling of the brow present in Case 2 are not recognized features of the syndrome. Both infants, however, showed fixed finger flexion and congenital heart disease, indication sufficient to warrant chromosome investigation.

The three previously reported cases with this form of mosaicism were all males. In that described by Warkany et al. (1962) there was fixed finger flexion; deformities of the toes; absent patellae; and asymmetry of the face and legs together with speech and motor defects. In this case there was unexplained heart failure but congenital heart disease was never proved. The other two males, who were unrelated, had generalized congenital analgesia and mild mental retardation (Beçak et al., 1963). 


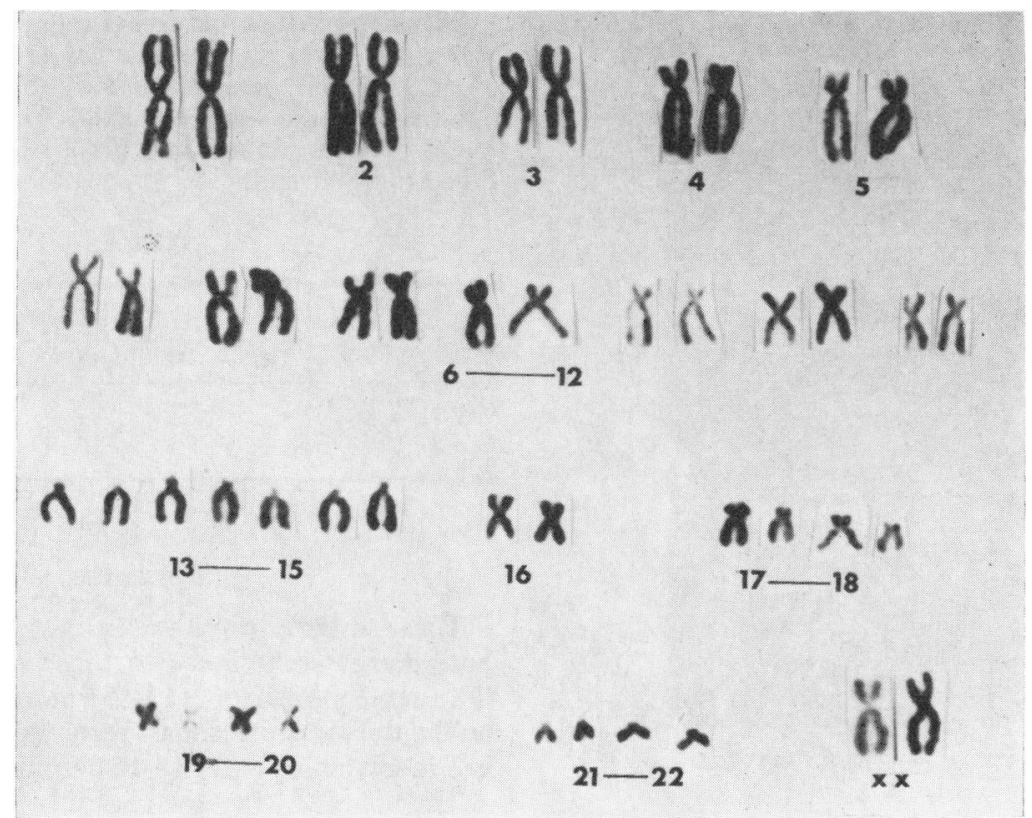

(a)

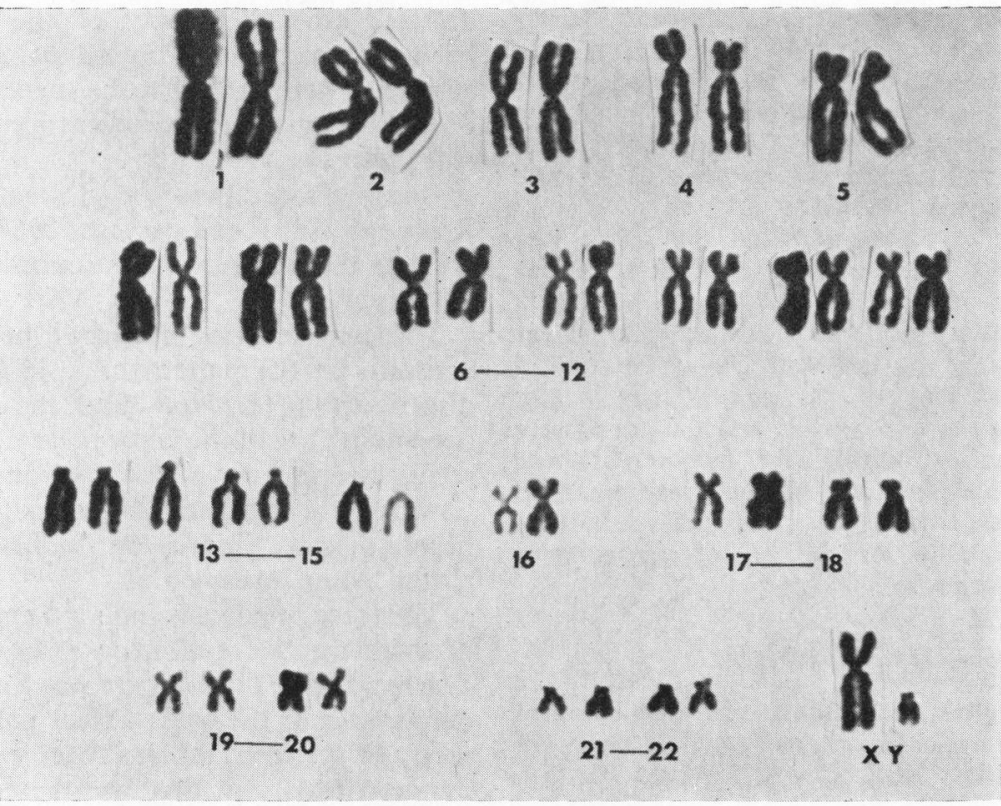

(b)

FIG. 3.-(a) 13-15 chromosomes from Case 1 (thymus), and (b) Case 2 (blood). 


\section{Summary}

Two cases of trisomic mosaicism for chromosomes 13-15 are reported. Each showed some of the features of trisomy 13-15 and both died in early infancy.

This work was supported by a grant from the Distillers Company Ltd., to the University of Edinburgh, and by the Board of Management, Royal Hospital for Sick Children, Edinburgh.

\section{REFERENCES}

Bain, A. D., and Gauld, I. K. (1964). The use of thymus and spleen in the demonstration of chromosomes post mortem in foetuses and infants. Brit. J. exp. Path., 45, 530.
Beçak, W., Beçak, M. L., and Schmidt, B. J. (1963). Chromosome trisomy of group 13-15 in two cases of generalised congenital analgesia. Lancet, 1, 664.

Marshall, R., Newnham, R. E., Rawstron, J. R., Ellis, J. R., and Stevens, L. J. (1964). Features of 13-15 trisomy syndrome with normal karyotype. ibid., 1, 556.

Moorhead, P. S., Nowell, P. C., Mellman, W. J., Battips, D. M., and Hungerford, D. A. (1960). Chromosome preparations of leukocytes cultured from human peripheral blood. Exp. Cell Res., $20,613$.

Patau, K., Smith, D. W., Therman, E., Inhorn, S. L., and Wagner, H. P. (1960). Multiple congenital anomaly caused by an extra autosome. Lancet, 1, 790.

Smith, D. W. Patau, K. Therman, E., Inhorn, S. L., and DeMars, R. I. (1963). The $\mathrm{D}_{1}$ trisomy syndrome. J. Pediat., 62, 326. Warkany, J., Rubinstein, J. H., Soukup, S. W., and Curless, M. C.
(1962). Mental retardation, absence of patellae, other malformations with chromosomal mosaicism. ibid., 61, 803. 